\title{
Los cuentos de infancia de Elena Garro y Julio Ramón Ribeyro
}

\author{
Paloma Torres ${ }^{1}$
}

Resumen. El artículo analiza comparativamente los relatos centrados en la infancia de la escritora mexicana Elena Garro y el peruano Julio Ramón Ribeyro, voces profundamente distintas pero que comparten una visión de la infancia que debe ser leída desde similares ejes teóricos.

Palabras clave: Elena Garro; Julio Ramón Ribeyro; cuento; infancia

\section{[en] The childhood stories of Elena Garro and Julio Ramón Ribeyro}

Abstract. The article analyses comparatively the childhood-centred stories of the Mexican writer Elena Garro and the Peruvian Julio Ramón Ribeyro, voices that are profoundly different but share a vision of childhood that should be read from similar theoretical axes.

Keywords: Elena Garro; Julio Ramón Ribeyro; story; childhood.

Sumario: 1. El imaginario de la infancia: una península dentro de la narrativa de Garro y Ribeyro. 2. La memoria: pasado, presente y futuro. 3. La semana de colores y la formulación de "lo previo". 4. Relatos santacrucinos y la formulación de "lo que permanece".

Cómo citar: Torres, P. (2021) Los cuentos de infancia de Elena Garro y Julio Ramón Ribeyro, en Anales de Literatua Hispanoamericana 50, 353-365.

No es vocación de este artículo hacer coincidir de manera artificial lo que sin duda es independiente, como lo son las voces de estos dos escritores profundamente distintos, pero sí mostrar la relevancia que, en ambos casos, cobra el estudio de sus cuentos de infancia y la pertinencia de leerles desde unos similares ejes teóricos. Tanto la mexicana Elena Garro como el peruano Julio Ramón Ribeyro pertenecen como escritores a la generación de los años cincuenta del siglo XX, que en México es llamada Generación de Medio Siglo y en el Perú marca el inicio de literatura de tema urbano, siendo Lima en ese tiempo una ciudad que ha crecido rápido, que cuenta ya con grandes barriadas y que está, tal y como la vio Ribeyro entonces, "madura para el tratamiento literario" (Ribeyro, 2009: 62) ${ }^{2}$.

Ambos autores han sido reconocidos tardíamente. Este desconocimiento se ha mitigado en una gran medida, y hoy Julio Ramón Ribeyro es considerado sin discusión uno de los mayores escritores de su país y de su tiempo, y Elena Garro una voz imprescindible de las letras mexicanas. Han proliferado también los estudios críticos que tratan sobre su calidad. Pero lo que sí prevalece en ambos casos es un carácter todavía discreto, que permite aportes críticos novedosos.

El reciente volumen Miradas sobre Elena Garro a cien años de su nacimiento ${ }^{3}$, que reúne la voz de especialistas e investigadores, se estructura precisamente en torno a este perfil olvidado de la autora. El relativo desconocimiento de Garro es citado con recurrencia por los estudios críticos. Rebecca Biron, en un

\footnotetext{
${ }^{1}$ Universidad Complutense de Madrid. España

E-mail: palomatps@gmail.com

${ }^{2}$ Se trata de una declaración recogida en Las respuestas del mudo, Iquitos: Tierra Nueva Editores, 2009, compilación de entrevistas a Julio Ramón Ribeyro, por Jorge Coaguila. En la página 199 del mismo volumen Ribeyro hace un recorrido por la novela peruana hasta llegar a la Segunda Guerra Mundial, cuando empiezan a aparecer las primeras barriadas o pueblos jóvenes. Lima se transforma, según Ribeyro, por la migración campesina, y se crean problemas de desocupación, vivienda, transporte, pequeña delincuencia. Todos estos elementos animaron a la escritura sobre Lima (Cfr.: 199).

${ }^{3}$ Publicado en marzo del año 2016 por la Universidad Autónoma de la Ciudad de México, coordinado por Grissel Gómez Estrada.
} 
artículo titulado "La modernidad mexicana según Elena Garro" habla de la "relativa ilegibilidad de Elena Garro" (Biron, 2016: 18). Daiset Ruiz escribe sobre su obra "poco reconocida" (Ruiz, 2016: 89), percibe un "anquilosamiento dentro de las discusiones en torno a su literatura" (Ruiz, 2016: 91), y también un olvido de su literatura "como consecuencia de los sucesos del 68 y su implicación política en los mismos" (Ruiz, 2016: 99).

Por su parte, Luzelena Gutiérrez de Velasco habla de "la soterrada censura que gravitó en torno a la persona y la obra de Garro durante muchos años, por cuestiones familiares y políticas" (Gutiérrez de Velasco, 2006). Y es importante constatar cómo, más allá de esta posible censura, y de acuerdo con Margarita León, a Elena Garro no le ha rodeado sólo el silencio, sino también la prevalencia de concepciones críticas erróneas acerca de su obra, como la que considera que su literatura "vive de espaldas a la historia y refugiada en los paraísos del realismo mágico" (León, 2004 (2)).

En cuanto a Julio Ramón Ribeyro, se le suele situar fuera del boom de la literatura hispanoamericana de los años sesenta y setenta del siglo pasado ${ }^{4}$. Ribeyro mostró una independiente fidelidad a su propia sensibilidad artística, que le apartó temporalmente de la fama. Es sabido que Ribeyro optó por el cuento en un momento de eclosión de la novela y por la prosa directa cuando a su alrededor triunfaban el barroquismo y la experimentación formal. En 1997, José Miguel Oviedo escribe un artículo en el que sentencia que los lectores no conocen bien a Ribeyro, le atribuye al autor una capacidad que parece voluntaria para pasar desapercibido y concluye que una adecuada lectura y una revisión crítica pertinente lo posicionarían como uno de los grandes:

Los lectores no conocen bien a Ribeyro. Es posible que, cuando su obra entera sea bien leída y juzgada descubramos que fue, sin que sus contemporáneos se dieran cuenta del todo, uno de los grandes que supo pasar desapercibido y que hizo del cuento una conducta moral a la que nunca renunció. Y entonces quizá nuestra visión de estos últimos cincuenta años de la vida del género sea otra y otras las reflexiones que nos inspire. $(\text { Oviedo, 1997: 53) })^{5}$

Si bien en la prosa de Elena Garro hay una mayor ductilidad en el lenguaje, una mayor apertura a lo mágico y a lo maravilloso ${ }^{6}$, y un juego libre con la manipulación del tiempo lineal, comparte con Julio Ramón Ribeyro una narrativa en el fondo directa y sencilla, orientada a la precisión narrativa, que no traspasa el umbral hacia la doble afectación ${ }^{7}$ y que es sensible a los dramas cotidianos de personajes discretos.

Ambos autores coinciden al dar protagonismo a personajes situados en los márgenes de la sociedad. La sensibilidad particular de estos personajes y los avatares del mundo externo no llegan nunca a aproximarse (parecen regirse por distintos parámetros), lo que acentúa su soledad. Por ejemplo, la de la señora Laurita, que en "La culpa es de los tlaxcaltecas" hace confidencias que no causan ningún efecto, o la de Efraín y Enrique en "Los gallinazos sin plumas", que cuando al fin consiguieron huir de su miserable situación, se encontraron con que la ciudad "despierta y viva, abría ante ellos su gigantesca mandíbula" (Ribeyro, 2010: 62).

Daiset Ruiz acentúa en un artículo titulado “"Orayá me salí del mundo': la no-persona en la novela 'Y Matarazo no llamó"” cómo "los relatos garrianos dan voz a los sin voz" (Ruiz 2016: 100). Y resulta significativo cómo el propio Ribeyro destaca precisamente que en la mayoría de sus cuentos se expresan "aquellos que en la vida están privados de la palabra, los marginados, los olvidados, los condenados a una existencia sin sintonía ni voz. Yo les he restituido este hálito negado y les he permitido modular sus anhelos, sus arrebatos y sus angustias" (Ribeyro, 2010: 10). Detectamos por lo tanto una coincidencia entre ambas literaturas desde esta perspectiva de dar voz a los discretos ${ }^{8}$ :

\footnotetext{
${ }^{4}$ Como escribió Diego Zúñiga en el prólogo a la edición chilena (Ediciones Universidad Diego Portales) de La caza sutil y otros textos: "No se piensa en el boom cuando se piensa en Ribeyro. No se piensa en Ribeyro cuando se piensa en el boom" (11).

${ }^{5}$ Esta cita y el párrafo que la antecede están incluidos en la tesis doctoral previa a esta investigación: Los cuentos de Julio Ramón Ribeyro: Estudio del final en los relatos de La palabra del mudo (UCM, 2015).

${ }^{6}$ También se puede encontrar en Ribeyro esta dimensión, pero está más circunscrita a algunos de sus cuentos: por ejemplo, a la trayectoria rocambolesca que hace la pelota en el cuento "El ropero, los viejos y la muerte", o con mayor propiedad a sus relatos fantásticos como "Doblaje" o "Ridder y el pisapapeles". En el caso de los cuentos que componen La semana de colores, de Elena Garro, la convivencia con lo maravilloso es más bien una constante transversal, y una línea que define su poética.

${ }^{7}$ Véase Julio Ramón Ribeyro. Prosas apátridas (1975): “[...] Toda tentativa para no ser afectado -monólogo interior, escritura automática, lenguaje coloquial-constituye a la postre una afectación en segunda potencia" (20).

${ }^{8}$ Discretos y, salvo excepciones, no estrictamente antiheroicos, no estrictamente marginales.
} 
En la vena de Nellie Campobello y Juan Rulfo, Elena Garro se interesó en las historias de personajes colocados en las orillas más frágiles de la vida comunitaria, a menudo hundidos en la pobreza [...]. “¿Quién se fija en mí? ¡Nadie! Nadie sabe ver a un pobre” (Beltrán Félix, 2016: 16).

Julio Ramón Ribeyro, por su parte, escribe:

Intenté captar y representar en lo que a mi juicio, y de acuerdo con mi propia sensibilidad, lo merecía: oscuros habitantes limeños y sus ilusiones frustradas, escenas de la vida familiar, Miraflores, el mar y los arenales, combates perdidos, militares, borrachines, escritores, hacendados, matones y maleantes, locos, putas, profesores, burócratas [...]. (Ribeyro, 2010: 10)

Ambos autores se aproximan, por lo tanto, en el sesgo de sus personajes. Y, también, desde un punto de vista más amplio, coinciden en una mirada "no totalizante" sobre la realidad y sobre la literatura.

En el citado libro Miradas sobre Elena Garro a cien años de su nacimiento Rebeca Biron expone cómo "en los años cincuenta y sesenta, siguiendo a Fernando Benítez, Jaime García Terrés y Paz", este grupo constituía "una hegemónica intelligentsia de vanguardia"9 (22-23), y cómo Garro critica "a los intelectuales que reclamaban el derecho a definir la modernidad nacional en nombre de todos los mexicanos" (Biron, 2016: 23):

¿Se puede decir que Elena Garro desarrolló una teoría coherente sobre la modernidad mexicana? No es una pregunta que suele hacerse, ya que una de las cosas que más distinguió a Elena Garro de otros escritores y pensadores de su época es que no pretendió explicarnos directamente, o de forma totalizadora, lo que es la mexicanidad o el pensamiento crítico moderno o el futuro político del país. (Biron, 2016: 21) ${ }^{10}$

Esta mirada distingue a Elena Garro en el marco de su contexto histórico, pero también permea a sus consideraciones acerca de sí misma y de su literatura. Es interesante, y no está exento de humor, un párrafo del mismo artículo en el que la autora rescata diversas oraciones de Elena Garro extraídas de varias entrevistas y cartas de la autora y que muestra la aceptación sin problematizarla de la contradicción y de los matices:

Soy trotskista, soy leninista, soy guadalupana monárquica. Soy feminista, soy antifeminista. Soy creadora del realismo mágico novelístico, que García Márquez copió de mí. No hay realismo mágico en mis textos. Soy narradora realista. El realismo no existe. Jamás quise ser escritora. No sé por qué no me respetan como escritora. Siempre estuve al lado de los estudiantes en el 68. No tuve nada que ver con el movimiento estudiantil. Octavio Paz es el gran amor de mi vida. Odio a Octavio Paz. (Biron, 2016: 21-22)

Por su parte, Julio Ramón Ribeyro despliega en su diario La tentación del fracaso una similar sensibilidad. Por ejemplo, en una entrada de su Diario madrileño (1955) con fecha del 28 de febrero, escribe: "Como siempre floto entre dos aguas, pico de aquí y de allá, rechazo y acepto con la mayor sangre fría ideas contradictorias, carezco en absoluto de "opiniones"” (Ribeyro, 2003: 56). O, en el texto 97 de sus Dichos de Luder, afirma: "Es penoso irse del mundo sin haber adquirido una sola certeza". En la misma línea, en respuesta una pregunta de Jorge Coaguila en Julio Ramón Ribeyro, la palabra inmortal, reflexiona: "La vida la concibo como algo completamente irracional, imprevisible, donde no hay lógica ni dirección u objetivo determinados; al menos, no perceptibles para los humanos. ¿Para qué existen los seres vivientes?" (Coaguila, 2009: 80).

Esta visión alejada de cualquier dogmatismo, dotada de una aceptación natural de la duda, e incluso de la contradicción, se traslada con claridad a su visión no totalizante de la literatura, de algún modo ya reflejada en su opción por la brevedad del género del cuento (que constituye la parte más extensa y relevante de su

\footnotetext{
${ }^{9}$ Cita a Deborah Cohn en "The Mexican Intelligentsia, 1950-1968: Cosmopolitanism, National Identity, and the State", Mexican Studies/Estudios Mexicanos, vol. 21, no. 1 (2005), pág. 143. Y da los nombres de la "generación de medio silo", que tiene un "rol central en la definición de la modernidad mexicana" (22).

${ }^{10}$ En el mismo artículo: "Según ella, lo más urgente no era el lugar de México en el escenario internacional -ya sea esto imaginado en términos raciales-étnicos, psicoanalíticos, económicos, políticos, culturales, literarios o intelectuales. Al contrario, creía que lo más urgente era la distancia entre el discurso de la libertad y la democratización, por un lado, y la realidad social represiva y exclusivista por otro lado" (23).
} 
producción literaria), y expresada con claridad en varias ocasiones, como en ésta en la que señala que "la interpretación total de la realidad" es tarea de la filosofía y no de la literatura:

¿Niega que la literatura pueda ofrecer una lectura total del mundo?

Así es (enciende un cigarrillo, fuma), porque creo que esa no es la misión de la literatura, sino la de la filosofía. Los filósofos tienen una forma de ejercer la inteligencia y el pensamiento con miras a una interpretación total de la realidad y del mundo. Yo pienso que esa es una función específica del filósofo y que al escritor le compete otra tarea. Una tarea que puede ir variando de escritor a escritor. Puede ser más ambicioso o menos ambicioso, pero da cuenta de hechos concretos que no van más allá de lo que quiere decir o, si van más allá, no es con la intención de hacer una interpretación global de la realidad. (Coaguila, 2009: 78)

Una vez aproximadas las poéticas de Julio Ramón Ribeyro y de Elena Garro, brevemente y partiendo de su coincidencia temporal, se propone en estas páginas una investigación de sus "cuentos de infancia".

\section{El imaginario de la infancia: una península dentro de la narrativa de Garro y Ribeyro}

Los "cuentos de infancia" de Elena Garro y Julio Ramón Ribeyro son cuentos de tono diferenciado respecto al resto de su narrativa corta, y esto merece atención. Constituyen una península particular respecto al resto de los relatos, una península que no se deslinda del resto de su cuentística y de sus características, pero cuyos contornos adquieren una singular independencia.

Por "cuentos de infancia" entendemos aquellos que atienden a esta etapa primigenia, ya sea por su protagonista infantil o por el rescate de escenarios que, a través de la memoria, reconstituyen la propia infancia de los creadores o el sentido profundo que éstos le han conferido. Julio Ramón Ribeyro escribió sobre la centralidad de este mundo infantil en el imaginario de su cuentística: "Mis cuentos, espejo de mi vida, pero también del mundo que me tocó vivir, en especial el de mi infancia y juventud" (Ribeyro, 2010: 10).

La mayoría de sus cuentos de infancia se reúnen en el último volumen de cuentos del autor, Relatos santacrucinos (1992). Este volumen reúne los cuentos "Mayo 1940", "Cacos y canes", "Las tres gracias", "El señor Campana y su hija Perlita", "El sargento Canchuca", "Mariposas y cornetas", "Atiguibas", "La música, el maestro Berenson y un servidor", "Tía Clementina" y "Los otros".

Los "cuentos de infancia" de la mexicana Elena Garro, que se encuentran por antonomasia en su primer volumen de cuentos La semana de colores (1964). La semana de colores incluye los relatos "La culpa es de los txalcalpecas", "El zapaterito de Guanajuato", "¿Qué hora es...?”, "La semana de colores", "El día que fuimos perros", "Antes de la Guerra de Troya", "El robo de Tiztla", "El Duende", "El anillo", "Perfecto Luna" y "El árbol".

En el prólogo a una muy reciente publicación que compila los cuentos de la autora y que da cuenta del interés por su narrativa corta, Geney Beltrán Félix se refiere "a un escenario arquetípico, ya imposible pero siempre añorado: el de esa cocina de la niñez" (Beltrán Félix, 2016: 14).

En el libro Testimonios sobre Elena Garro, Patricia Rosas Lopátegui recuerda cómo “cuando Elena visitó México después de casi veinte años de un autoexilio forzoso, en La Jornada del 3 de noviembre de 1991 [Emmanuel] Carballo, en entrevista con Patricia Vega, hizo un retrato global bastante significativo sobre Elena [...]:", en el que afirmó: "“Creo que la religión de Elena es la infancia y la mayor influencia en su literatura es ella misma en sus primeros años de vida"” (Rosas Lopátegui, 2002:11).

Proponemos profundizar en la dimensión que la infancia adquiere en ambos autores. Pero en primer lugar, antes de transitar este camino, es preciso establecer una delimitación. Si bien es probado que el corpus a cuya lectura nos enfrentamos contiene documentadas vivencias personales de ambos escritores, no nos interesa desarrollar en estas páginas el espacio existente entre el texto de infancia y su correlato autobiográfico. Ribeyro llegó a afirmar: "lo que antes les sucedía a mis personajes, ahora, en estos últimos cuentos, me sucede a mí" (Coaguila, 2009: 52), e incluso observó una evolución en su narrativa corta, que pasó de dar "voz a los sin voz" a reproducir la suya propia:

La palabra del mudo es la palabra de la gente que no tiene posibilidad de expresarse. Mientras que ahora es mi voz, es la mía, se ha convertido en eso. La palabra del mudo, cuarto tomo, soy yo. El mudo que estaba callado y que, de pronto, habla y aparece con nuevos campos (Coaguila, 2009: 36-37) 
Sin embargo, nos interesa en estas páginas la memoria de la infancia no como vivencia originaria y contrastable en el texto resultante de cada autor, sino en la medida en que es forjadora de la poética posterior, instigadora de los asuntos que se tratarán después y acicate de la mirada literaria que se desarrollará a partir de esas experiencias primigenias. ${ }^{11}$

\section{La memoria: pasado, presente y futuro}

Atendamos, para comenzar, a la raíz conceptual del término "memoria", según la expone Aristóteles en la Metafísica.

Según el filósofo, los animales "nacen dotados de sensación, y a partir de ella se genera en algunos la memoria y en otros no. Ello explica que los primeros sean más inteligentes y más aptos para el aprendizaje que los que no pueden recordar [...] Excepto el hombre, todos los animales viven de recuerdos e imágenes y no participan sino escasamente de la experiencia. Por el contrario, el género humano posee además arte y razonamientos. A partir de la memoria nace en los hombres la experiencia: varios recuerdos de una misma cosa terminan por constituir el ser de una única experiencia" (Aristóteles, 2014: 41-42).

Es reveladora esta afirmación, pues se observa que en contra de lo que intuitivamente puede parecer, y siempre según Aristóteles, es la memoria la que posibilita la experiencia, y no al revés. El recuerdo es compartido con los animales e inferior a la memoria, ya que es esta última la que, aunando varios recuerdos constituye la experiencia. La memoria crea la experiencia. No todos los recuerdos se constituyen en experiencia (y por ello, por ejemplo, los primeros nueve años que Elena Garro pasó de niña en la Ciudad de México no aparecen apenas en sus escritos, y sin embargo los cuatro años que pasó en Iguala determinan su personalidad y marcan el sesgo de su literatura ${ }^{2}$ ). En este sentido el proceder de la memoria y el de la misma escritura se aproximan. El proceso de la memoria, como el del relato, extrae un "argumento", selecciona de las vivencias y recuerdos lo relevante, destila lo que ha de permanecer, en un movimiento de desechar aquello que no ha sido significativo. ${ }^{13}$

En el argumento, por su naturaleza, hay tensión entre el pasado, el presente y el futuro, es la línea que une $\mathrm{y}$ en la que se funda o descansa la tensión narrativa. ${ }^{14}$. Una tensión forjada por el comienzo, el nudo, y el desenlace en el argumento clásico, y que puede aplicarse tanto a la experiencia como a la literatura. De alguna manera, el nudo deja atrás el comienzo, que es el germen del pasado que anuncia el presente, y todo relato se orienta teleológicamente hacia su (futuro) final ${ }^{15}$. Ante un relato, o ante una vida, se pregunta ¿qué sucedió? Pero no en busca de un resumen aséptico: de aquello que sucedió, ¿qué es relevante para el que presente (para el presente del relato, o para el que hoy soy, para la literatura que de entonces emanó)? ¿Qué sucede hoy que vaya a influir en el futuro? ¿Y qué sucederá después, influido por lo que hoy sucede?

Las partes del argumento están profundamente imbricadas y forman parte de su esencia ${ }^{16}$, de modo que el argumento se convertiría en otro si se retirara una sola de sus partes. Precisamente por esta síntesis (que se atribuye a la memoria y al argumento literario y que es síntesis de pasado, presente y futuro) puede exclamar

${ }^{11}$ En el caso de Elena Garro, nos alineamos de este modo con la perspectiva que expresa Reynol Pérez Vázquez en el homenaje póstumo que le dedicó a la autora en el diario Reforma (“¿Cuándo tendré un hogar sólido?”), con las palabras que recoge Rosas Lopátegui en Testimonios...: "Desde su regreso definitivo a México en junio de 1993, Elena Garro se convirtió en un personaje público, perseguido más por su tormentosa relación con Octavio Paz que por la innegable calidad de su obra literaria. Quienes se acercaron a la figura de Elena Garro a través del escándalo de "notas culturales" deberán ahora aproximarse a su obra y aquilatarla en su justa medida [...]" (15).

${ }^{12}$ Según destaca Patricia Rosas Lopátegui en Testimonios sobre Elena Garro: "La familia Garro Navarro se traslada a Iguala aproximadamente a mediados de 1926, porque Elena recuerda que el "viaje coincide con el momento en que empezó la persecución religiosa" (Emmanuel Carballo, op. cit., pág. 498). Entonces, Elena vivió en la capital mexicana los primeros nueve años de su vida, de 1916 a mediados de 1926 ; después radia de 1926 a 1930 en Iguala, y la familia Garro Navarro regresa a la ciudad de México a finales de 1930 o principios de 1931 . Curiosamente, veremos que Elena hizo escasas referencias a esos primeros nueve años de su vida en la ciudad de México. La experiencia de la infancia que marcará su vida serán los años de Iguala" (62).

${ }^{13}$ En relación a la novela garriana Los recuerdos del porvenir, Margarita León escribe: "La memoria de Ixtepec celebra simbólicamente un rito de reconstrucción de los discursos anteriores. Rescata y reordena los materiales de construcción de los discursos anteriores. Rescata y reordena los materiales de los recuerdos y de la experiencia que se encontraban dispersos, en un estado caótico, amorfo. Realiza así un acto de fundación, de consagración del tiempo y del espacio, un acto de "sacrificio necesario" para dotar a los recuerdos de significación" (16-17).

${ }^{14} \mathrm{Y}$ esta unidad entre pasado, presente y futuro será determinante, como veremos, en el caso de los cuentos de infancia de Elena Garro.

${ }^{15}$ Esta última referencia al final, cfr. Marco Kunz. El final de la novela..., pág. 21.

${ }^{16}$ Véase Aristóteles, Métafísica, Libro VII (Z), Capítulo tercero. La esencia es nombrada en estas páginas como una de las cuatro acepciones fundamentales de la substancia. Y así, "la esencia de cada cosa es lo que se dice que es por sí misma cada cosa: así, ser tú no es (15) ser músico, pues no eres músico en virtud de ti mismo. Lo que tú eres por ti mismo es tu esencia” (227). 
Elena Garro "Yo sólo soy memoria", la cual sería una declaración absurda si la memoria se refiriera únicamente al pasado, como comúnmente suele entenderse ${ }^{17}$.

Desde esta perspectiva según la cual en el seno de la memoria comparecen el pasado, el presente y el futuro, la lectura de los cuentos de infancia de Elena Garro contenidos en La semana de colores y la de los cuentos de infancia de Julio Ramón Ribeyro contenidos en los Relatos santacrucinos, nos llevan a plantear dos principios o ejes relacionados con el tiempo que pueden aplicarse a ellos: a saber, "lo previo" y "lo que permanece". No pretendemos una sistematización rígida en torno a estos dos conceptos, ya que ambos se encuentran muchas veces mezclados y presentes con distinto nivel de intensidad en un mismo cuento de infancia de cualquiera de los dos autores cuyo estudio nos ocupa. Lo que pretendemos es señalar una tendencia dominante o clarificadora de la presencia de la memoria en cada volumen de cuentos.

\section{La semana de colores y la formulación de "lo previo"}

Desde este punto de vista, podemos afirmar que los cuentos de infancia de Elena Garro se articulan en torno al principio de "lo previo". Lo previo, por su sola formulación, no se basta a sí mismo, hace inmediatamente referencia a otra cosa: algo es previo a otro algo. Lo previo se sitúa en el pasado pero hace referencia a lo que está por venir, es un movimiento proyectivo del pasado hacia el futuro, y este movimiento se produce singularmente en los cuentos de Elena Garro. Esta pulsión proyectiva ha sido señalada por la misma autora: "La memoria del futuro es válida". (Carballo: 503$)^{18}$

Los cuentos de La semana de colores muestran el mundo infantil como el mundo "previo", el "antes de". Es un mundo puro en el sentido de nítido, que anticipa el futuro pero todavía está plenamente libre de él. Es anterior, y en él las fuerzas primigenias comparecen con toda rotundidad. ${ }^{19}$

Véase parte del relato de su infancia que la escritora Elena Garro envía a Emmanuel Carballo y que se reproduce en el libro Protagonistas de la literatura mexicana:

Mis padres fueron José Antonio Garro y Esperanza Navarro, dos personas que vivieron siempre fuera de la realidad, dos fracasados, y que llevaron a sus hijos al fracaso. A mis padres sólo les gustaba leer, y a sus hijos no nos gustaba comer. Nunca teníamos apetito; o nos daba pereza masticar: 'Que les hagan papilla a los chicos', ordenaba mi padre. A Esperanza, mi madre, le gustaban únicamente los dulces y los pasteles. José Antonio en cambio amaba los buenos platillos como su hija Estrellita, la menor de nosotros. [...]

Ellos me enseñaron la imaginación, las múltiples realidades, el amor a los animales, el baile, la música, el orientalismo, el misticismo, el desdén por el dinero y la táctica militar leyendo a Julio César y a Von Clausewitz. Mientras viví con ellos sólo lloré por Cristo y por Sócrates, el domingo en que bebió la cicuta, cuando mi padre nos leyó los Diálogos de Platón, que no he releído. [...]

Mis padres me permitieron desarrollar mi verdadera naturaleza, la de 'partícula revoltosa', cualidad que heredó mi hija Helena y que los sabios acaban de descubrir. Estas 'partículas revoltosas' producen desorden sin proponérselo y actúan siempre inesperadamente, a pesar suyo. En mi casa podía ser rey, general mexicano, construir pueblos con placitas, casas, calles, cuartel e iglesia en el enorme jardín por el que paseábamos en burro o a pie. Mi casa estaba en Iguala, Guerrero, es decir, una de mis casas. También construimos un teatro y teníamos títeres. A veces me convertía en merolico y salía a vender ungüentos para curar todos los males. Mi ayudante era Boni, mi primo predilecto, menor que yo y con el que me escapaba cargando dos 'máuseres' para buscar la Laguna. Los arrieros nos devolvían a la casa insolados, con las narices y la frente peladas por el sol. [...]

El 18 de agosto era mi santo. Mi tío Boni, el hermano de mi padre, joven y viudo, me enviaba con su criado don Félix un regalo cada hora. Tal vez adivinó que luego en el mundo ${ }^{20}$ nadie iba a regalarme nada y quiso

${ }^{17}$ En su obra Caminos del reconocimiento, Paul Ricoeur hace alusión a la afirmación de Agustín de Hipona "Medimos los tiempos cuando pasan" (XI, 21, 27 de las Confesiones, BAC; Madrid, 1997) y concluye: "Luego, es en el espacio anterior del alma donde se despliega la famosa dialéctica entre distentio e intentio: distensión entre las tres orientaciones del mismo presente, presente del pasado en la memoria, presente del futuro en la anticipación, presente del presente en la intuición [...]. El alma es como el tiempo, paso del futuro hacia el pasado a través del presente" (156).

${ }^{18}$ Así lo declara la autora en carta a Emmanuel Carballo, para Protagonistas de la literatura mexicana. Unas páginas más adelante, en el desarrollo de su análisis de "La semana de colores" Carballo escribe que en esos relatos "el pretérito condiciona el presente y anuncia cómo será el porvenir" (520).

${ }^{19}$ Según el mismo Emmanuel Carballo: "La principal aportación de Garro es haber traído un mundo que antes no se había trabajado en la literatura latinoamericana, un mundo lleno de magia, de la gracia anterior al pecado original” (Rosas Lopátegui, Testimonios: 12; el subrayado es mío). 
compensarme. Yo tenía una flotilla de veleros azules con velas blancas, una hermana Deva, que según se afirmaba en la familia descendía de los pájaros y un hermanito, al que tirábamos a la fuente para ver 'cómo se ahogaba'. Toni, el perro, se echaba al agua para salvarlo y nos ladraba furioso. [...]

Ah, pero un día el profesor Rodríguez descubrió que yo era una gran escritora. Nos dio a redactar una invitación para un 'baile en palacio' y yo puse la palabra 'gentileza'. Con gran felicidad le anunció a mi padre que no debía preocuparse por mis desmanes, que yo sería una gloria nacional. Todos los Garro le debemos mucho al profesor Rodríguez, figura tierna, sabia y encantadora de mi infancia. Él traía las noticias terribles de lo que sucedía fuera de mi casa: la política, los fusilamientos y los robos. ‘¡Un maestro es sagrado!', nos decía mi padre con los ojos despidiendo chispas verdes, como una advertencia. [...]. (Carballo, 2005: 506-507)

De estos párrafos creo que resulta significativo entresacar la partícula "luego en el mundo", que la autora refiere al hilo del relato de su relación con su tío Boni, pues de ella se deduce con claridad que estas experiencias de la infancia no pertenecen al mundo, sino que se sitúan antes de él, y fuera de él. Representan el "antes de". La incorporación al mundo llegará después. Las experiencias infantiles suceden "antes" de ese futuro que será el mundo, y que se sabe que va a llegar pero aún no ha comparecido: son "previas". Queda delimitado con toda claridad, diferenciado de otros, el tiempo de la infancia. Y también el relato de esa infancia que la autora vuelca en La semana de colores. Pues es significativo cómo este libro de relatos también representa "el antes", "lo previo" a algunos asuntos que luego la autora desarrollará profundamente más adelante. Por ejemplo, uno de los más destacados temas recurrentes de la poética de Elena Garro es la huida. Es revelador que el siguiente volumen de cuentos de la autora sea "Andamos huyendo, Lola", y el cuento que le da título un relato de una madre y una hija que se esconden en lo que parece ser un extraño edificio destinado a los refugiados y huidos, y en el que ellas se encuentran a disgusto y viven en permanente sospecha y con sensación de amenaza.

Esta línea maestra de su temática no la encontramos en los cuentos de "La semana de colores", que conteniendo en su seno toda la intensidad de la tragedia, se regodean en la vivencia infantil, que es un lugar nítido en el que permanecer: podemos pensar simbólicamente en aquel jardín en el que la autora y su hermana Deva "crecían como pantas" y en la clara aserción de Garro: "Me preguntas: ¿¿Crees en la felicidad?' Sí, porque me acuerdo que la practiqué en la infancia” (Carballo, 2005: 505).

El tiempo de la infancia que se encapsula en La semana de colores es un tiempo de desarrollo de la "verdadera naturaleza", la original, la primigenia, la que marcará la literatura posterior con una libertad creadora que ya no se trastocará ("En mi casa podía ser rey, general mexicano, construir pueblos con placitas, casas, calles, cuartel e iglesia en el enorme jardín por el que paseábamos en burro o a pie”). Esta libertad personalísima se mantendrá durante todo el desarrollo posterior de la literatura de Elena Garro, y será el marco independientemente del tema escogido.

Un ejemplo de este tiempo "previo" y por lo tanto "diferenciado" de la infancia que es recreado por la memoria es el cuento es "El día que fuimos perros". En este relato las niñas protagonistas, Eva y Leli, despiertan a las seis de la mañana ("y supimos que era un día con dos días adentro" (Garro, 2016: 76). En este día singular las niñas son perros y se echan al lado de Toni, el perro de la casa:

Junto a Toni la casa había perdido peso. Por el suelo del día caminaban dos hormigas; una lombriz se asomó por un agujerito, la toqué con la punta de un dedo y se volvió un anillo rojo. Había pedazos de hojas, trocitos de ramas, piedras minúsculas y la tierra negra olía a agua de magnolia. El otro día estaba a un lado. Toni, Eva y yo, mirábamos sin miedo sus torres gigantescas y sus vientos fijos de color morado. (Garro, 2016:77)

En un momento dado, Rutilio, el criado, les llama, pero lo hace "desde el otro día":

¡¿Dónde van, mocosas desgraciadas? -les gritó Rutilio desde el otro día. (Garro, 2016:79)

El fogón con las cenizas encendidas, Candelaria, Rutilio, los cantos y las brujas, pasaban delante de los ojos de los perros como figuras proyectadas en un tiempo ajeno. Las palabras de Rutilio circulaban por el corredor sin fondo de la casa y no nos tocaban (Garro, 2016: 81) ${ }^{21}$

\footnotetext{
${ }^{20}$ El subrayado es mío.

${ }^{21}$ Se revela aquí una de las muchas aristas que puede adquirir la escritura a través de la memoria en el caso de Elena Garro. Uno de los rasgos de la "región" de la infancia es que es "intocada" incluso por el mismo tiempo en la formulación de la misma Elena Garro. En La memoria del tiempo. La experiencia del tiempo y del espacio en Los recuerdos del porvenir de Elena Garro, Margarita León reproduce el siguiente fragmento de la novela: "En aquel tiempo hasta el dedal de su madre brillaba con una luz diferente mientras iba y venía construyendo abejas y margaritas. Algunos de esos días habían quedado aparte, señalados para siempre en la memoria, colgados de un aire especial. Luego el mundo se volvió opaco, perdió sus olores penetrantes, la luz se suavizó, los días se hicieron iguales y las gentes adquirieron estaturas enanas. Quedaban todavía lugares intocados por el tiempo como la carbonera con su luz. (32)" (20). Ante esto, explica: "La memoria hecha discurso, hecha escritura, resulta
} 
Los dos días dentro de un mismo día permanecen diferenciados hasta el final del cuento. Escribe Emmanuel Carballo, sobre los cuentos de La semana de colores que "la realidad cede su sitio a la magia o por lo menos lo corta con ella" (Carballo, 2005: 520), pero lo que observamos es que la manipulación libre del tiempo lineal y la posibilidad de animalización de las niñas mediante el juego no corta la realidad u ocupa su sitio, sino que son recursos que de manera extraordinaria están al servicio de la "exactitud" en el retrato de esa misma realidad. Este relato describe con magistral exactitud psicológica el estado de la infancia y la configuración distinta que el tiempo adquiere durante este período vital. Sólo al final del cuento se produce un despertar y una modificación de este tiempo infantil, final al que nos referiremos en páginas posteriores. Pero esto sucede únicamente en las últimas líneas. Todo el desarrollo del cuento se ha ocupado de fijar ese momento "previo", ese "antes".

"Lo previo" adquiere singular independencia y está "intacto", "intocado". Pero, a su vez, tal y como se expuso en páginas anteriores, implica una referencia presente hacia el futuro, implica un movimiento proyectivo del pasado hacia el futuro.

Ese futuro que Elena Garro incorpora a la memoria y que es un horizonte presente por la tensión que en el pasado existe hacia él (por ello hemos preferido el concepto de "lo previo", cuya primera acepción, según el Diccionario de la Real Academia Española es "Anticipado, que va delante o que sucede primero", formulación referencial al futuro) se identifica en sus cuentos con el destino tal y como éste se entiende en la Grecia Clásica, imaginario muy presente en la poética garriana y que influye en su concepción del tiempo ${ }^{22}$.

En Testimonios sobre Elena Garro, Patricia Rosas Lopátegui recoge la voz de Alfonso González y Beth Miller para afirmar que para Elena Garro "hay dos grandes momentos en la historia de Occidente, Atenas y el romanticismo alemán" 23 .

Uno de los cuentos reunidos en el volumen La semana de colores se titula significativamente "Antes de la guerra de Troya". Las protagonistas son de nuevo dos hermanas, Eva y Leli, que sustraen el libro que su madre esconde bajo la almohada y que resulta ser La Ilíada. Se lo llevan a la copa de un árbol y allí, entre las hojas verdes, comienzan una lectura que va a transformar su tiempo y la percepción de sí mismas. Véase que el cuento no se titula "La guerra de Troya", sino que se le añade con toda intención el "Antes", pues es ese "antes" el que va a quedar trastocado, alterado, al terminarse el cuento.

Y, así:

Antes de la guerra de Troya los días se tocaban con la punta de los dedos y yo los caminaba con facilidad. El mundo era tangible. Nada escapaba de mi mano y yo formaba parte de este mundo. Eva y yo éramos una. [...] La voz de Eva era la mía. (Garro, 2016: 82)

El comienzo de "la desdichada guerra de Troya" marca a su vez textualmente el comienzo del desenlace del cuento, que se precipita desde ese momento hacia su preciso final, unas páginas más adelante. Un final ya contenido en el adjetivo "desdichada". Un final que es "destino" inevitable, que está señalado y se cierne sobre el personaje, al igual que sucede en la obra griega. La memoria contiene el pasado y el futuro. La irrupción del destino condiciona el tiempo de "lo previo". "Antes de la guerra de Troya fuimos dos en una" (Garro, 2016: 87). La guerra de Troya (leída a partir de un libro significativamente, sustraído del mundo adulto, que les aguardaba pero todavía no, que aún escondía ese secreto) provoca un despertar a la edad adulta que altera profundamente su realidad y les produce extrañeza respecto al mundo que habitan. Leli está con Héctor y Eva está con Aquiles. Ya no son una, sino que están enfrentadas la una a la otra, descubren la alteridad: frente a la hermana ("Yo la miré. Estaba a horcajadas sobre la rama del árbol, como otra persona que no fuera yo misma" (Garro, 2016: 86)) y frente al mundo ("Miré la casa y sus tejados torcidos me desconocieron" (Garro, 2016: 86). Junto a la alteridad, se descubre la soledad: "Y con Héctor empecé a conocer el mundo a solas" (Garro, 2016: 86). Y esta soledad no es solo de ellas, sino que se extrapola también al propio Aquiles y al propio Héctor ("También ellos giraban en el Reino de las Sombras, sin poder acostumbrarse a su condición de almas en pena. Por las noches yo oía a Héctor arrastrando sus armas. Eva escuchaba los pasos de Aquiles y el rumor metálico de su escudo" (Garro. 2016: 87), seres presentes e influyentes en el futuro aunque provengan del pasado ${ }^{24}$.

ser el centro o vértice en el cual es posible que confluyan pasado, presente y futuro, donde pueden encontrarse personajes que pertenecen a distintas épocas. La memoria hecha escritura, o dicho de otro modo, la escritura o discurso de la memoria, puede poner de manifiesto 'la realidad intacta', el 'instante"' (20).

${ }^{22}$ Cfr. Margarita León. La memoria del tiempo..., parte II, capítulo II, págs.171-182.

${ }^{23}$ Beth Miller y Alfonso Gozález, ibíd., pág. 219. La formación de la escritora en el romanticismo alemán será recogida unas páginas más adelante.

${ }^{24}$ A este respecto, y en relación a la memoria del pueblo de Ixtepec que es el eje de la novela de Elena Garro Los recuerdos del porvenir, Margarita León escribe: "Los ixtepecanos son un pueblo, como Troya, que resiste estoicamente el cerco tendido por sus enemigos. Los antecedentes y la 
El destino, según el Diccionario de Filosofía de Ferrater Mora ${ }^{25}$, Tomo Primero, se define de la siguiente manera. Por su interés, trasladamos a estas páginas a pesar de su extensión, la entrada, no completa, pero sí con la suficiente amplitud para ofrecer un mínimo contexto y llegar hasta el lugar que interesa:

DESTINO. El problema de la naturaleza y sentido del destino fue abundantemente tratado por los filósofos antiguos, especialmente durante el período helenístico-romano. Estoicos, platónicos, epicúreos, eclécticos, etc. expresaron opiniones sobre el destino - si existe, lo que es, cómo puede conocerse, si es o no compatible con la libertad, etc. [...] Varios escritos producidos durante el período helenístico-romano llevan por título De fato, [...] El término latino fatum significa, al parecer, "lo predicho" (por un oráculo), el conjunto de "las cosas dichas" (fata) acerca del porvenir. Aunque, según apuntamos, fatum es prácticamente equivalente

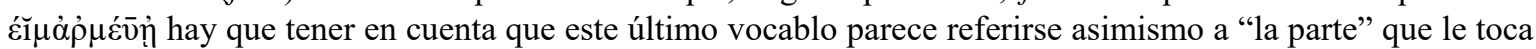
a cada hombre (y, en general, a cada ente) dentro de la serie de acontecimientos que constituyen "la trama" del universo. Los dos sentidos pueden, por lo demás, fundirse en uno: el "destino" es definible entonces como "la suerte" que le "toca" a cada cosa (y en particular a cada hombre) en tanto que sea en principio cognoscible o enunciable por medio de oráculos, intuición y hasta reflexión racional. [...].

En efecto, por un lado conviene distinguir entre destino y azar, destino y determinismo (v.) (universal), destino y predestinación (v.). [...] Entre los filósofos contemporáneos que han tratado de la noción de destino figura Spengler. Según este autor, la idea de destino se opone radicalmente al principio de causalidad. El destino es para Spengler un símbolo que se refiere al Universo-historia y cuya comprensión es intuitiva, en tanto que la causalidad se refiere al Universo-Naturaleza, es lógica y racional. El destino se halla relacionado con la vida; la causalidad, con la muerte. Por eso el destino, que "es a la causalidad lo que el tiempo es al espacio", representa la "necesidad ineludible de la vida", y por eso también "la historia real se halla grávida de destino, pero no tiene ley" (Det Untergang des Abendlandes, 1923, t. 1, pág. 156). Esta concepción del destino es rechazada, en cambio, sin mencionarla explícitamente, por Scheler, para quien la idea spengleriana aparecería sólo como una ciega determinación de carácter biológico. "Exigimos del destino ciertamente dice Scheler-que nos afecte involuntariamente y casi siempre imprevisiblemente, pero que represente, sin embargo, algo distinto de la serie de datos y acciones sometida a la violencia causal; a saber: la unidad de un sentido que lo anima todo, que representa en el hombre y en torno a él la conexión esencial e individual entre el carácter humano y el acontecer. Lo peculiar del destino lo constituye precisamente esto: que al contemplar el panorama de una vida entera o de una larga serie de años o acontecimientos, sentimos tal vida como absolutamente contingente en cada caso particular, pero cuya conexión, por muy imprevisible que haya sido el acontecer de cada uno de sus miembros, refleja precisamente eso que creemos que constituye el núcleo de la persona en cuestión" (Ordo amoris, trad. Zubiri, 1934, págs. 113-114). Scheler hace, en suma, del destino la expresión de ese núcleo emocional — sistema de preferencias o repugnancias o ethos subjetivo- en que consiste el hombre. Por eso el destino es independiente del querer y del deseo, así como del acontecimiento objetivo real. (Ferrater Mora, 1956: 429-430)

La primera parte de la definición sitúa la preocupación por el destino en el marco del período helenísticoromano, lo cual aproxima esta definición al contexto de la Ilíada, que en el cuento "Antes de la guerra de Troya" y en distintas entrevistas a la autora, cobra importancia. Asimismo, se aproxima a la poética de la autora la definición que unifica las dos acepciones primero señaladas, la que considera el destino como " $\mathrm{La}$ suerte' que le 'toca' a cada cosa". Y así, la primera adhesión de las dos protagonistas del cuento con Aquiles o con Héctor se realiza de manera intuitiva, determinada según su propio ser, les toca "en suerte", no es escogida tras de una larga reflexión (después se reafirmará esta toma de partido en dos ocasiones más durante el mismo cuento, ya con mayor determinación), pero la primera (y distinta) adhesión es un descubrimiento nuevo, que se produce de manera "súbita", un descubrimiento que "sucede", insospechado por las protagonistas:

"No permitas que los perros devoren mi cadáver", decía Héctor por tierra, alzando el brazo para apoyar su súplica. Aquiles, de pie, con la cabeza apoyada en la garganta del caído, lo miraba desdeñoso.

- ¡Pobre Héctor!

- Yo estoy con Aquiles — contestó Eva súbitamente desconocida.

(Garro, 2016: 85)

Después ellas mismas conceden toda la radicalidad posible a este peso nuevo del destino, inevitable, que trasforma su mundo conocido, que altera profundamente su mundo "previo", "antes" y lo torna en uno que es

esencia de todos ellos se hallan -según los ve la memoria de su pueblo y según se ven a sí mismos- en el pasado de los grandes personajes clásicos, los de la Iliada y La Odisea, los de las Sagradas Escrituras” (León Vega, p.25)

25 Tomo I, Montecasino, Buenos Aires: Editorial Sudamericana, 1956, 5a edición, págs. 429-430. Disponible en: https://profesorvargasguillen.files.wordpress.com/2011/10/jose-ferrater-mora-diccionario-de-filosofia-tomo-i.pdf 
un futuro angustioso en el que Leli ya no se reconoce: "El olor a vainilla ya no era vainilla [...] Yo no tocaba nada, estaba fuera del mundo. [...] y las palabras fueron inútiles, porque también ellas se habían vaciado de su contenido [...] Héctor y Aquiles se paseaban en el Reino de las Sombras y Eva y yo los seguíamos, pisando agujeros negros" (Garro, 2016: 86).

El destino, tal y como comparece en los cuentos de La semana de colores, va aproximándose a unos u otros aspectos de la anterior definición. Se liga a la muerte en "El árbol”, en "¿Qué hora es...?”, en "Perfecto Luna", en "Nuestras vidas son los ríos" o a la "necesidad de la vida" en "Era mercurio", por ejemplo. Pero tal vez la acepción que más se aproxima a la poética de Elena Garro tomada en general sea la última de Scheler, según el cual el destino, situado más allá del curso de la realidad histórica, "refleja precisamente eso que creemos que constituye el núcleo de la persona en cuestión", como se observa con claridad en el caso de Eva y Leli, que descubren su mismidad y diferencia nuclear en "Antes de la guerra de Troya". En esta misma línea de acentuación de la subjetividad, cobra relevancia en el universo garriano, por último, la final apreciación de Ferrater Mora sobre Scheler, quien "hace, en suma, del destino la expresión de ese núcleo emocional - sistema de preferencias o repugnancias o ethos subjetivo - en que consiste el hombre. Por eso el destino es independiente del querer y del deseo, así como del acontecimiento objetivo real".

\section{Relatos santacrucinos y la formulación de "lo que permanece"}

Los cuentos de infancia de Julio Ramón Ribeyro, recogidos principalmente en los Relatos santacrucinos, podrían agruparse en torno al principio de "lo que permanece". "Lo que permanece" acoge simbólicamente estos cuentos que narran la infancia y juventud del escritor en el barrio limeño, y alude a una dimensión temporal y también a una dimensión ontológica, refiriéndose a aquello que, teniendo su raíz en el pasado, efectivamente y en el presente configura a ese ser que recuerda. Así como "lo previo" implicaba en los cuentos de Elena Garro un movimiento proyectivo del pasado hacia el futuro, "lo que permanece" parece implicar un movimiento proyectivo desde el presente hacia el pasado. Se rescata del pasado aquello que por su carácter relevante o insólito ha quedado prendido en la sensibilidad del escritor. No en todos los casos se llega narrativamente de manera explícita al presente de la enunciación (como sí sucede, por ejemplo, en "Los otros" o en "Mayo 1940"), pero en todos los casos se relatan los recuerdos que, desde el presente en el que se está produciendo la escritura, se consideran significativos.

En este sentido, y en palabras de Peter Elmore sobre el volumen Relatos santacrucinos:

Si bien la casa familiar, la escuela y el barrio son los escenarios de las anécdotas, éstas no tienen que ver con la rutina y el ritmo usual de la existencia; por el contrario, los hechos que han calado en la memoria del cronista son los que rompen [...] la uniformidad del paisaje social y doméstico (Elmore, 2002: 41)

Nos encontramos ante una clásica mirada hacia el pasado desde el presente. Atendiendo a la literalidad de la definición aristotélica de memoria que se refirió en páginas anteriores, los cuentos de infancia de Julio Ramón Ribeyro iluminarían esa concepción según la cual la memoria es creadora de experiencia, escoge el recuerdo que se ha constituido en experiencia y que, por lo tanto, marca al ser presente.

El cuento "Mayo 1940" (sin fechar en la edición utilizada) da comienzo al volumen y ejemplifica este movimiento de la memoria desde el presente hacia el pasado, y la influencia de éste sobre aquel. La ciudad de Lima, entonces una ciudad limpia, apacible y familiar, según el relato, sufre un terremoto en mayo de 1940. Al narrador anónimo y a su hermano les sorprende a la salida del colegio. Consiguen llegar a casa donde su madre respira aliviada al verlos. Allí escuchan por la radio las noticias de las muertes y de las zonas más afectadas, y esperan al resto de la familia. La madre nerviosa enciende velas a la virgen de la Inmaculada. Llegan la hermana mayor y después la menor. Sólo falta el padre, que por fin hace su aparición. Se relaja la tensión y, al ver la casa en pie, el padre reconoce que es un buen edificio, y afirma que le edificará un segundo piso. El narrador reflexiona al final del cuento acerca de la influencia de aquel terremoto. La conciencia de esta influencia -de un hecho pasado- pertenece ya al presente de la enunciación. El cierre del relato dice así: 
Solo con el correr de los años nos daríamos cuenta de que ese terremoto que no destruyó nuestra casa había removido el fondo de los seres y de las cosas, que ya no volvieron a ser lo mismo ${ }^{26}$. Fue como una señal que marcó una fractura en el tiempo: nuestra infancia había terminado; Lima perdería pronto su encanto de sosegada ciudad colonial; el conflicto europeo se extendió a otros continentes para convertirse en la más mortífera guerra de la historia. Y en cuanto al segundo piso del que habló papá, nunca se llegó a construir. Por eso nuestra casa, a pesar de estar terminada nos dejó siempre la impresión de algo inconcluso, como este relato. (Ribeyro, 2010: 909)

Sólo desde el presente, y a través de la memoria, es posible conferirle al recuerdo del pasado su hondura y calado. Hay una intervención de la propia subjetividad que, como se verá más adelante, cobra importancia. El terremoto de mayo de 1940 alteró de manera permanente y no transitoria ("no volvieron a ser lo mismo") "el fondo de los seres y las cosas". Se conectan también de manera singular varias rupturas, en una gradación que va desde el plano personal ("nuestra infancia había terminado"), al contexto próximo de la ciudad ("Lima perdería pronto su encanto") y al conflicto mundial ("se extendió a otros continentes para convertirse en la más mortífera guerra de la historia"). Esta triple "fractura" sucedió en el pasado, pero es permanente porque ha marcado el tiempo presente y es desde el presente desde donde se toma conciencia de su influencia. Esta toma de conciencia es un descubrimiento amargo en este caso, donde la memoria de la infancia convive con la nostalgia.

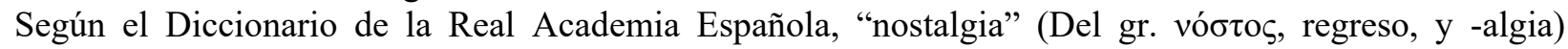
significa, en su segunda acepción: "Tristeza melancólica originada por el recuerdo de una dicha perdida.". Un ejemplo paradigmático sería el cuento ribeyriano "Los eucaliptos". El peruanista José Miguel Oviedo identifica este cuento en Narradores peruanos con "líricas evocaciones de la infancia" (Oviedo, 1968: 19). En Ribeyro en dos ensayos Miguel Gutiérrez sitúa este cuento entre los "evocativos y nostálgicos" (Gutiérrez, 1999: 20-25), y Cristanto Pérez Esáin, en Cuentos, lo aproxima a los cuentos autobiográficos referidos a "recuerdos infantiles" 28 .

Este relato pertenece al volumen Cuentos de circunstancias, pero es pertinente consignarlo aquí en referencia a los Relatos santacrucinos, por su contenido, y por las declaraciones que el mismo Julio Ramón Ribeyro esgrime durante una entrevista con Jorge Coaguila ${ }^{29}$ :

También usted se ha referido, volviendo a Relatos santacrucinos, en anteriores cuentos al mismo ambiente de Miraflores de la década de 1940, al mismo ambiente infantil, como en "Los eucaliptos" o como en "Página de un diario". ¿Tenía ya ese deseo de escribir sobre esos ambientes antes mencionados?

-Sí, en efecto. Ocurre que muchos de mis libros son más bien como compendios de cuentos de diferentes tendencias, de diferentes épocas, de diferentes intenciones, como esos relatos que cita usted y que pertenecen a Cuentos de circunstancias. Obviamente, si algún día tuviera que reeditar mis cuentos, los reagruparía de acuerdo con nuevos criterios. Por ejemplo, incluiría esos cuentos que ha mencionado usted en Relatos santacrucinos e ir así pasando cuentos de un libro a otro para que constituyan series homogéneas. (Coaguila, 2008: 52)

Escrito en Múnich ${ }^{30}$, en 1956, el narrador de "Los eucaliptos" rememora su infancia y las transformaciones de su barrio hasta la tala de estos árboles que eran el único símbolo que permanecía intacto (recuérdese el concepto garriano del territorio de la infancia como "lo intocado"), y que cae también finalmente con la llegada de los nuevos tiempos.

El personaje constata con nostalgia los cambios en el entorno que él tiene idealizado de su niñez. Es un personaje pasivo, que contempla y queda pensativo, que no pasa a la acción de intentar detener la poda. Asume de este modo como inevitables esos cambios, y esa sensación de inevitabilidad le lleva a la inacción.

\footnotetext{
${ }^{26}$ El subrayado es mío.

${ }^{27}$ Cfr. Miguel Gutiérrez.

${ }_{28}$ Cfr. Crisanto Pérez Esáin.: Cuentos-Julio Ramón Ribeyro: 34-35. Por su parte, Giovanna Minardi remite fundamentalmente a la distinción propuesta por Tzvetan Todorov entre el aspecto semántico (grado de mímesis, verosimilitud del texto, objetivo o subjetivo), el aspecto verbal (la relación de la voz narrante con la materia narrada y la perspectiva dominante) y el aspecto sintáctico. Minardi sitúa el cuento "Los eucaliptos" en el aspecto semántico, como cuento autobiográfico. Cfr. Giovanna Minardi. La cuentística de Julio Ramón Ribeyro (2002).

${ }^{29}$ Entrevista “Tres", fechada en 1992, y recogida en Ribeyro, la palabra inmortal. Lima: Tierra Nueva Editores, 2008.

${ }^{30}$ Los tres párrafos que siguen, referidos al cuento "Los eucaliptos", están contenidos con ligeros cambios en la tesis doctoral que antecede a esta investigación: Los cuentos de Julio Ramón Ribeyro. Estudio del final en los relatos de 'La palabra del mudo' (UCM, 2015).
} 
Según el análisis de Peter Elmore en El perfil de la palabra, "el deslinde con la infancia y el paso a una nueva etapa no se experimenta como un avance; por el contrario, se trata de un despojo que invita no a la comunicación y la apertura, sino al silencio y al ensimismamiento" (Elmore, 2002: 66).

El narrador utiliza la primera persona del plural (atípica en la cuentística ribeyriana), y esta elección le confiere al cuento un carácter social, amplía el alcance de las palabras desde la nostalgia individual a la nostalgia compartida, constituyendo éstas no un monólogo personal, sino (aunque parece referirse a él y sus hermanos, o a él y a sus amigos), el discurso de toda una generación.

El mundo de la infancia que se narra (aquel lugar y aquel tiempo) aparece como cerrado y clausurado, sólo queda su permanencia mediante el recuerdo, que comparece en el presente.

La ciudad progresó. Pero nuestra calle perdió su sombra, su paz, su poesía. Nuestros ojos tardaron mucho en acostumbrarse a ese pedazo de cielo descubierto, a esa larga pared blanca que orillaba toda la calle como una pared de cementerio. Nuevos niños vinieron y armaron sus juegos en la calle triste. Ellos eran felices porque lo ignoraban todo. No podían comprender por qué nosotros, a veces en la puerta de la casa, encendíamos un cigarrillo y quedábamos mirando el aire, pensativos. (Ribeyro, 2010: 181)

Se constata en estas líneas el movimiento nostálgico del presente hacia el pasado. Este movimiento provoca la no comparecencia del futuro. La calle "perdió su sombra, su paz, su poesía" y los ojos "tardaron mucho en acostumbrarse". Ribeyro problematiza la interpretación nostálgica de sus Relatos santacrucinos en entrevista con Jorge Coaguila:

Por confrontar el Miraflores de los años cuarenta con el actual, algunos pueden interpretar que usted está en contra de la modernidad, puesto que presenta un Miraflores en un periodo bastante remoto y agradable.

-Sí, ocurre que cuando uno relata escenas de su infancia siempre se tiene un cierto tono de nostalgia, que se puede interpretar como que lo pasado fue mejor. Sin embargo, esta sería una interpretación errada. Pero, en efecto, como usted habrá notado, gran parte de esos relatos santacrucinos están hechos desde una perspectiva contemporánea, y esto simplemente para verificar los cambios y las transformaciones habidas. Creo que no es para lamentar la existencia de un Miraflores moderno, pienso que hay que aceptar esa transformación a la modernidad. Las ciudades no pueden permanecer idénticas a sí mismas. Si no, no habría ningún progreso. (Coaguila, 2008)

Sin embargo, y a pesar de este reparo, se puede mantener como tesis la tensión de "lo que permanece", en un movimiento de la memoria proyectivo desde el presente hacia el pasado, con un sesgo nostálgico que implica la no comparecencia del futuro. Véase, como ejemplo, que en los cierres de ambos relatos citados, "Mayo 1940" y "Los eucaliptos", hay referencias explícitas al futuro: en el primero, se hace alusión al carácter inconcluso de la casa y del mismo relato, y en el segundo se alude a las nuevas generaciones que llegan y juegan, llenando de vida el transformado barrio. Sin embargo, la apertura hacia el futuro es sólo aparente ${ }^{31}, \mathrm{y}$ convive con una fuerte sensación de clausura en ambos relatos, en los que la pérdida del pasado ha quedado efectivamente narrada.

${ }^{31}$ Esta apariencia de apertura fue una de las conclusiones del estudio del final ribeyriano en Los cuentos... Aparece ahora de un modo nuevo en estas páginas, ligada a la memoria ribeyriana, tal y como esta se expresa en sus cuentos de infancia. El hecho de que la alusión al futuro o incluso al mismo carácter inconcluso del texto conviva en el relato ribeyriano con una fuerte sensación de clausura del relato, como si ese futuro citado no alterara lo narrado ni lo por venir, se liga con el esceptismo ribeyriano y probablemente con su concepción del tiempo histórico. Al respecto, una pregunta de Jorge Coaguila en La palabra inmortal:

Se observa que usted tiene una idea la Historia pendular o circular, en aquello del eterno retorno. En la "nota del autor" de Cambio de guardia escribe: "Las sociedades tienden a veces a efectuar movimientos pendulares o circulares y en estas condiciones lo pasado puede ser lo futuro, lo presente lo olvidado y lo posible lo real.

-Claro. Por ejemplo, se pensó en cierto momento que todos los países se iban a orientar al socialismo y, de pronto, a fines de la década de 1980, todo ese ideal terminó repentinamente. Es decir, todos los héroes, todos los mitos, todos los emblemas del socialismo fueron derribados de un momento a otro. Ver las estatuas de Lenin, que en determinada época eran consideradas sagradas, tiradas al suelo con cadena nadie lo iba a prever. Anoche, viendo un documental, observaba, cuando estalló la Revolución rusa, cómo las estatuas del zar eran exactamente derribadas al piso como las estatuas de Lenin setenta años después. Aquel sueño del socialismo desapareció y volvemos a un período de predominio capitalista, liberal. Pero eso no me convence mucho, porque Marx puede regresar. [...] Lo cual llegaría a corroborar lo que digo: que la historia no es lineal, que hay el eterno retorno" (81-82). 


\section{Referencias bibliográficas}

Aristóteles (2014). Metafísica. Intr., trad. y notas de María Luisa Alía Alberca. Madrid: Alianza Editorial.

Beltrán Félix, Geney (2016), "Prólogo", en Elena Garro. Cuentos completos. Madrid: Alfaguara.

Biron, Rebecca (2016), "La modernidad mexicana según Elena Garro", en Grissel Gómez Estrada (coord.). Miradas sobre Elena Garro a cien años de su nacimiento. México: UACM y Ediciones del Lirio, págs. 17-37.

Carballo, Emmanuel (2005). Protagonistas de la literatura mexicana. México: Alfaguara.

Coaguila, Jorge (2008). Ribeyro, la palabra inmortal. Iquitos: Tierra Nueva Editores.

Elmore, Peter (2002). El perfil de la palabra. La obra de Julio Ramón Ribeyro. Lima: Fondo de Cultura Económica.

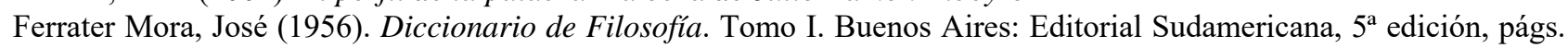
429-430. Disponible en: https://profesorvargasguillen.files.wordpress.com/2011/10/jose-ferrater-mora-diccionariode-filosofia-tomo-i.pdf

Garro, Elena (2016). Cuentos completos. Madrid: Alfaguara.

Gutiérrez, Miguel (1999). Ribeyro en dos ensayos. Lima. Editorial San Marcos.

Gutiérrez de Velasco, Luzelena (2006), "La memoria del tiempo. La experiencia del tiempo y del espacio en Los recuerdos del porvenir de Elena Garro, de Margarita León”, Nueva Revista de Filología Hispánica, vol. LIV, nº. 1, enero-junio 2006, págs. 261-265.

León, Margarita (2004a). La memoria del tiempo. La experiencia del tiempo y del espacio en Los recuerdos del porvenir de Elena Garro. México: UNAM.

---- (2004b), "Entrevista concedida a Ángel Vargas", La Jornada, 20 de diciembre de 2004.

Oviedo, José Miguel (1968). Narradores peruanos Antología. Caracas: Monte Ávila Editores.

(1997), "Algunas reflexiones sobre el cuento y su proceso en Hispanoamérica", en Patrick Collard (coord.). El relato breve en las letras hispánicas actuales. Madrid: Rodopi, págs. 41-53.

Pérez Esaín, Crisanto (2008). Cuentos Julio Ramón Ribeyro. Berriozar: Cénlit Ediciones.

Ribeyro, Julio Ramón (2008). La tentación del fracaso. Barcelona: Seix Barral. Editores.

- (2009). Las respuestas del mudo. Edc. y comp. de Jorge Coaguila. Lima: Tierra Nueva (2010). La palabra del mudo. Barcelona: Seix Barral.

Rosas Lopétegui, Patricia (2002). Testimonios sobre Elena Garro. Monterrey: Ediciones Castillo.

Ruiz Sarquis, Daiset (2016): “'Ora sí ya me salí del mundo': la no-persona en la novela Y Matarazo no llamó...”, en Grissel Gómez Estrada (coord.). Miradas sobre Elena Garro a cien años de su nacimiento. México: UACM/Ediciones del Lirio, págs. 87-118.

Zúñiga, Diego (2012), “A la orilla del mundo”, en Julio Ramón Ribeyro. La caza sutil y otros textos. Santiago de Chile: Universidad Diego Portales. 